\title{
Explicationist Epistemology and the Explanatory Role of Knowledge
}

\author{
Erik J. Olsson ${ }^{1}$ (i) \\ Published online: 8 April 2021 \\ (C) The Author(s) 2021
}

\begin{abstract}
It has been argued that much of contemporary epistemology can be unified under Carnap's methodology of explication, which originated in the neighboring field of philosophy of science. However, it is unclear to what extent epistemological theories that emphasize the explanatory role of knowledge fit into this picture, Kornblith's natural kind epistemology and Williamson's knowledge first approach being cases in point. In this connection, I raise three questions. Can we harvest the insights of these approaches without loss in the more standard and less idiosyncratic explicationist framework? Can we do so without falling prey to prominent criticism raised against those approaches? Finally, do the approaches come out as coherent under an explicationist rendering? I argue that in Kornblith's case the answer to all three questions is essentially in the affirmative. Much of the knowledge first approach is also translatable into explicationism. However, from that perspective, Williamson's central argument for treating knowledge as undefinable, referring to persistent yet unsuccessful attempts to solve the Gettier problem, amounts to an overreaction to that problem. Leaving explicationism aside, I ask, in the penultimate section, what Williamson's own philosophical method really amounts to.
\end{abstract}

Keywords Explication · Rudolf Carnap · Timothy Williamson · Hilary Kornblith · Knowledge first · Natural kind

\section{Introduction}

The notion that epistemology, as it is currently pursued, is in good shape could be questioned. There are many seemingly conflicting accounts of central epistemological concepts such as knowledge, justification, coherence, and so on. There is nothing even approaching consensus in sight on many if not most topics. Even more discomforting is the fact that there are a number of seemingly conflicting methodologies and general approaches out there: conceptual analysis, experimental epistemology, formal epistemology, knowledge first, knowledge as a natural kind-again, the list goes on. While conceptual analysis has

Erik J. Olsson

erik_j.olsson@fil.lu.se

1 Department of Philosophy, Lund University, Helgonavägen 3, entré D, 22362 Lund, Sweden 
been more widely advocated than its methodological competitors, it is vulnerable to the paradox of analysis and the notorious Gettier problem.

As a remedy, Olsson (2017) proposed that Carnap's method of explication, with its roots in philosophy of science, could be a suitable vehicle for unifying epistemology and coming to grips with some of its long-standing problems. The unificatory benefits would include all the systematic advantages that normally follow from something being subsumable under a general and historically respectable standard methodology, e.g. in terms of well-foundedness and facilitated communication, cooperation, cross-fertilization and comparison (e.g. Cat 2017). Olsson suggested two ways of looking at current methodologies in Carnapian light: they can either be viewed as degenerate limit cases of explication or, more charitably and constructively, as sub-methodologies under a Carnapian methodological umbrella. Olsson also argued that neither the paradox of analysis nor the Gettier problem arises within an explicationist framework.

In this paper, I intend to take this unificatory project further by assessing the extent to which the works of two highly influential contemporary epistemologists-Hilary Kornblith and Timothy Williamson-whose most salient communalities are an emphasis on the explanatory role of knowledge combined with an aversion towards conceptual analysis, fit into an explicationist picture. Thus, my purpose here is not to evaluate their epistemological theories. On the contrary, I will assume for the sake of the argument that their insights into matters epistemological are bona fide insights. My main questions are rather the following:

1. Can we harvest the insights of these approaches without significant loss in the more standard and less idiosyncratic explicationist framework?

2. Can we do so without falling prey to prominent criticism against those approaches? The focus will be on one particular critique, which highlights what I will refer to as the problem of access and explain in due course.

3. Do the approaches come out as internally coherent under an explicationist rendering?

My main claims will be the following. Insights in Hilary Kornblith's natural kind epistemology translate without much effort into explicationist vocabulary. This is so without us thereby becoming vulnerable to the problem of access. The result is a coherent natural kind epistemology founded on a solid and historically respectable methodology. Williamson's case turns out to be slightly more complex. While much of what he says regarding knowledge and its explanatory role can be appreciated by an explicationist, sometimes in a qualified sense, this is less so for his central (Gettier) argument for claiming that knowledge cannot be defined in terms of necessary and sufficient conditions. ${ }^{1}$

In Sect. 2, I summarize Carnap's account of explication and Olsson's recent work on explicationist epistemology. I proceed, in Sect. 3, to address Kornblith's natural kind epistemology from the perspective of explicationism. After that, I turn to Williamson. Leaving explicationism aside for the moment, I ask, in the penultimate section, what Williamson's

\footnotetext{
1 Why the focus on Kornblith and Williamson? One answer is that Olsson (2017) does not give an explicationist perspective on their undertakings and yet the latter are of undisputed value and originality. Having said this, the choice of the two is to some extent arbitrary; there are many other distinguished epistemologists for whom the same question could be raised: can their insights be accommodated within an explicationist framework? Yet, if we want further to explore the potential of such a framework to unify epistemology, we need to begin somewhere.
} 
own philosophical methodology amounts to. I summarize and discuss my findings in the concluding section.

\section{Explicationist Epistemology}

By explication, Carnap explains, "we mean the transformation of an inexact, prescientific concept, the explicandum, into a new exact concept, the explicatum" (Carnap 1950, 3). The method of explication, a form of (rational) conceptual reconstruction, thus involves two steps. The first step amounts to the elucidation of the explicandum. What is the more specific intuitive concept to be explicated? The second step amounts to the specification of the explicatum. What is the exact concept that is to replace the explicandum in particular contexts and for particular purposes?

An explicatum should satisfy the following conditions as well as possible (Carnap 1950, 7): it should be similar to the explicandum, exact, fruitful and simple. Carnap is rather specific regarding the more precise interpretation of these desiderata or requirements:

1. The explicatum [the thing that explicates] is to be similar to the explicandum [the thing that is explicated] in such a way that, in most cases in which the explicandum has so far been used, the explicatum can be used; however, close similarity is not required, and considerable differences are permitted.

2. The characterization of the explicatum, that is, the rules of its use (for instance, in the form of a definition), is to be given in an exact form, so as to introduce the explicatum into a well-connected system of scientific concepts.

3. The explicatum is to be a fruitful concept, that is, useful for the formulation of many universal statements (empirical laws in the case of a nonlogical concept, logical theorems in the case of a logical concept). ${ }^{2}$

4. The explicatum should be as simple as possible; this means as simple as the more important requirements (1), (2) and (3) permit.

Carnap's paradigm example of the explication of an empirical concept is the reconstruction of the concept of fish in zoology, i.e. the replacement of the ordinary concept of fish by the somewhat artificial concept of piscis, to use Carnap's term, defined by the properties "live in water, are cold-blooded vertebrates, and have gills throughout life" (Carnap 1950, 6). The new explicatum excludes several kinds of animal that were subsumed under the concept fish, e.g. whales and seals. At the same time, it is sufficiently close in meaning to fish to replace the latter in zoological contexts. It is more fruitful because it allows for the formulation of a greater number of interesting general truths since piscis have more properties in common. ${ }^{3}$ Carnap's examples of explication in logic include Frege's definition of natural number and Tarski's definition of truth.

A more recent empirical example, mentioned in Cordes and Siegwart (2019), is the 2006 redefinition of the concept of planet by the International Astronomical Union (IAU),

\footnotetext{
${ }^{2}$ One would have expected "many true universal statements". See Gustafsson (2013) for a discussion of Carnap's view on explication and truth.

3 The example is mainly intended to illustrate the sense in which the explicatum should be similar to the explicandum and the relevant kind of fruitfulness; Carnap does not comment on the relative exactness and simplicity of the new concept piscis. Furthermore, I am told by a biologist that the current concept of fish in biology, as of 2019, includes some warm-blooded creatures as well.
} 
according to which a planet is "a celestial body that (a) is in orbit around the Sun, (b) has sufficient mass for its self-gravity to overcome rigid body forces so that it assumes a hydrostatic equilibrium (nearly round) shape, and (c) has cleared the neighbourhood around its orbit" (IAU 2006). The new explicatum has the noteworthy consequences that Pluto no longer counts as a planet. Following Cordes and Siegwart (2019), it still incorporates key aspects of the earlier use patterns, while being at the same time more exact and fruitful. $^{4}$

Explicationist philosophy refers, in my terminology, to this general view on the nature of philosophical definitions, which, in an updated version, may recognize other kinds of concept than just logical or empirical, e.g. legal or ethical concepts. Explicationist philosophy should be understood to imply that all four requirements on an explicatum be given substantial positive weight. ${ }^{5}$ Explicationist epistemology, or simply "explicationism", is the corresponding approach applied to the particular field of epistemology. ${ }^{6}$

At the time of writing there is an increasing interest in explication as an important philosophical methodology. ${ }^{7}$ One way of relating explicationist epistemology to other methodologies is to view the latter as degenerate or improper limit cases of the former. In particular, three schools (suitably qualified) can be reconstructed as assigning zero (or very low) weight to all requirement on an explication, except the first: similarity to the ordinary concept (Olsson 2017). They are Oxford style ordinary language philosophy, experimental epistemology (e.g. Weinberg et al. 2001) and, not least, standard conceptual analysis. By contrast, epistemic logic and formal epistemology, in their more extreme forms, can be understood as assigning positive weight to all requirements on an explication, except similarity which is assigned zero or very low weight. To be sure, most epistemic logicians and formal epistemologists are interested in securing some similarity with the corresponding ordinary language terms, although the focus is surely on the other requirements (fruitfulness, exactness, simplicity). Alternatively, other methodologies such as the above can be viewed, more charitably and constructively, as sub-methodologies under a Carnapian methodological umbrella. Thus, a number of

\footnotetext{
${ }^{4}$ Cordes and Siegwart (2019) do not comment on the relative simplicity of the new definition of "planet".

5 Carnap does not cleanly separate the first desideratum - similarity - from its relative weight. He tells us not only that similarity is a desideratum, but also, in the same breath, that it need only be minimally satisfied. When I discuss the ranking of the desiderata in the following, I take the first desideratum to be similarity to our ordinary concept simpliciter. Thus, I do not view Carnap's additional note about how much similarity between explicandum and explicatum is required as part of the desideratum itself. Thanks to Martin Jönsson for pointing this out. With this in mind, Carnap's view on the relative weights are: that fruitfulness and exactness are the two most important requirements, and equally so, followed by similarity and simplicity, in that order. For an alternative assessment, ranking fruitfulness before exactness, see Dutilh Novaes and Reck (2017).

${ }^{6}$ Notable advocates of explication include Quine (1960), Lehrer (1990) and Maher (2007), although the relation to Carnap's own account of explication is sometimes not entirely clear (regarding Quine, see Martinsson, 2013). Similar ideas can be found in Hempel (1952). Apart from Olsson, Lehrer (1990) and Baumann (2016) advocate explication as their method of choice in epistemology. Olsson (2017) argues that Goldman (1999) implicitly assumes explication or a similar methodology when equating knowledge with true belief for the purposes of (veritistic) social epistemology.

7 Brun (2016) is a useful and informed overview of the state of the art, including the challenges that face practitioners of explicationism. Brun identifies what he sees as limitations in Carnap's account and suggests, in response, various ways in which the methodology could be developed. My own approach has been, and still is, to depart from Carnap's account in his 1950 treatise only if absolutely necessary, but one could of course disagree about the point at which this condition kicks in.
} 
philosophers have pointed out that experimental epistemology can be useful in elucidating the explicandum. ${ }^{8}$

While it is true that conceptual analysis has been more widely advocated than other methodologies, it suffers from two long-standing problems. One is the paradox of analysis: an analysis is either uninformative (if correct) or false (if incorrect). How can an account that is either uninformative or false be of any value? Take for instance the JTB analysis of knowledge in terms of justified, true belief. If that analysis is correct, it amounts to an analytic truth; if not, it is false. The shorter the analysis, the more pressing the paradox. An analysis of knowledge in terms of a complex set of necessary and sufficient conditions, if correct, can be enlightening in the same sense in which a complex mathematical theorem can. There is no similar problem for explicationist epistemology, the aim of which is not to capture meaning relations in natural language or relations of conceptual priority, but to identify, for a particular purpose, a more exact and fruitful correlate of the explicandum, ideally in a scientific or logical framework, while respecting the value of simplicity.

Additionally, conceptual analysis has to grapple with the long-standing Gettier problem in ways that explication does not (Olsson 2015). I will spend some time on this point since it plays an important role in my account of Williamson's theory in Sect. 4. Suppose someone proposes an explication of knowledge along the following lines:

(K) $\mathrm{S}$ knows that $\mathrm{p}$ if and only if $\mathrm{C}$.

Suppose C entails, presumably wrongly, that people do know in Gettier cases. Does it follow that $(\mathrm{K})$ fails to be a good explication of knowledge? To see why the answer is no, consider again the first Carnapian desideratum:

The explicatum [the thing that explicates] is to be similar to the explicandum [the thing that is explicated] in such a way that, in most cases in which the explicandum has so far been used, the explicatum can be used; however, close similarity is not required, and considerable differences are permitted.

For the Gettier problem to be a threat to the claim that $(\mathrm{K})$ satisfies this desideratum it would have to imply that it is not the case that: in most cases in which the ordinary concept of knowledge has so far been used, the condition $\mathrm{C}$ in $(\mathrm{K})$ can be used instead. But it does not imply this: Gettier predicaments are simply too rare. After all, they involve the occurrence of two independent improbable events (one unfortunate, the other one lucky): a proposition (Brown owns a Ford) that is strongly supported by evidence turns out nonetheless to be false and yet by luck (Brown happens to be in Barcelona of all places) the target proposition (Brown owns a Ford or is in Barcelona) comes out true anyway. By probability theory, the occurrence of two independent events each of which is improbable is even less probable, in fact much less probable, than those individual events in isolation. Therefore, the Gettier problem is certainly not a knock-down argument against an explication of knowledge; whether the explication is successful will depend on the extent to which there is similarity with the explicandum in other respects and the extent to which the other Carnapian desiderata are satisfied ${ }^{9}{ }^{10}$

As many authors have pointed out (e.g. Pinder 2017; Dutilh Novaes and Reck 2017; Koch 2019), Carnap's account of fruitfulness seems rather restrictive. Thus Koch (2019),

\footnotetext{
${ }^{8}$ For example, Shepherd and Justus (2015), Olsson (2017), Shupbach (2017) and Koch (2019).

${ }^{9}$ See Olsson (2012) and, in particular, Olsson (2015) for a sustained defense of the reliabilist account of knowledge as an explication, taking into account all four Carnapian requirements.

${ }^{10}$ Explicationist epistemology represents a seriously pluralistic approach to epistemology. See Olsson (2017) for an elaboration on this point.
} 
702) writes: "However, this is too narrow as a construal of fruitfulness, in particular with respect to philosophy. For some purposes, formulating either empirical laws or logical theorems is not what really matters-just think of typical philosophical inquiries, e.g. into the nature of justice or knowledge ... [T] rather a cluster of criteria, not all of which have to be satisfied in a given instance." On a broader account, any improvement of a theory occasioned by the addition of a concept would count in favor of the fruitfulness of the latter (not only improvement in the system of laws). Thus, we may distinguish between narrow ("nomological", "theorem-oriented") and broad ("holistic") fruitfulness and, correspondingly, between a narrow or broad explicationist methodology. This distinction, which is my only significant departure from Carnapian orthodoxy, will be useful when we turn to Williamson in Sect. 4.

\section{Explication and Natural Kind Epistemology}

Hilary Kornblith is best known for his theory of knowledge as a natural kind. His starting point, in his 2002 book Knowledge and Its Place in Nature (KPN), is his rejection of conceptual analysis in favor of the thesis that "the subject matter of epistemology is knowledge itself, not our concept of knowledge" (p. 1). One attractive aspect of conceptual analysis is that it suggests a method by means of which we can proceed, namely, by probing our intuitions about the concept in question. It is less clear how intuitions, or anything else for that matter, could guide us if the subject matter is the phenomenon itself, rather than our conception of that phenomenon. Kornblith addresses this issue early on in KPN:

Intuitions must be taken seriously in the absence of substantial theoretical understanding, but once such theoretical understanding begins to take shape, prior intuitive judgments carry little weight unless they have been endorsed by the progress of theory. The greater one's theoretical understanding, the less weight one may assign untutored judgment. [...] Thus, appeal to intuition early on in philosophical investigations should give way to more straightforwardly empirical investigations of external phenomena $(2002,14-15)$.

The picture Kornblith eventually arrives at, by relying on empirical science, is one according which knowledge, in the sense of reliably acquired true belief, is a natural kind:

I want to claim that knowledge is, in fact, a natural kind. [...] I take natural kinds to be homeostatically clustered properties, properties that are mutually supporting and reinforcing in the face of external change. [...] The knowledge that members of a species embody is the locus of a homeostatic cluster of properties; true beliefs that are reliably produced, that are instrumental in the production of behavior successful in meeting biological needs and thereby implicated in the Darwinian explanation of the selective retention of traits $(2002,61-62)$.

As such, knowledge plays a crucial explanatory role in animal and human behavior in ways revealed, more specifically, by the science of cognitive ethology: 
Knowledge explains the possibility of successful behavior in an environment, which in turn explains fitness. [... W]e must appeal to a capacity to recognize features of the environment, and thus the true beliefs that [... someone] acquire[s] will be the product of a stable capacity for the production of true beliefs. The resulting true beliefs are not merely accidentally true; they are produced by a cognitive capacity that is attuned to its environment. In a word, the beliefs are reliably produced. The concept of knowledge which is of interest here thus requires reliably produced true belief (2002, 57-58). ${ }^{11}$

Clearly, Kornblith thinks that reliabilist knowledge, in the sense of reliably acquired true belief, plays an important explanatory role in virtue of being related to other biologically important properties by empirical laws.

Now it is true that, for Kornblith, what is related to biologically interesting properties and therefore important is knowledge itself, as a phenomenon in the natural world, not the concept of knowledge. For Carnap, by contrast, importance or, to use his preferred term, fruitfulness is a property of our concepts: it is, in the empirical case, the property an explicatum has in virtue of figuring in many true lawlike generalizations in the scientific theory in which it appears. However, it should be clear that these are little more than two ways of talking about one and the same thing. More precisely, the following principle establishes a bridge between Kornblith's and Carnap's accounts of importance or fruitfulness:

(Phenomenon-Concept Bridge Principle) A phenomenon $\mathrm{X}$ is important in the sense of being an important part of the portion of reality belonging to scientific domain $Y$ just in case the concept of $\mathrm{X}$ is fruitful (in Carnap's sense) in the true account of Y.

In particular, the phenomenon of knowledge is an important part of the portion of reality studied in cognitive ethology just in case the concept of knowledge, explicated as reliabilist knowledge, is fruitful (in Carnap's sense) in the true account of that portion of reality.

We can now translate Kornblith's epistemology into explicationism broadly as follows. His central claim is that knowledge is an important part of the portion of reality studied in cognitive ethology. He, moreover, thinks that reliabilism gives the correct account of such knowledge. By the Phenomenon-Concept Bridge Principle, this translates into the claim that the reliabilist concept of knowledge is a fruitful concept once introduced in cognitive-ethological theory. If we assume, presumably with Kornblith, that current cognitive-ethological theory is a "well-connected system of scientific concepts", to use Carnap's phrase, then explicating knowledge in this way also satisfies the desideratum of exactness. See Olsson (2015) for arguments to the effect that the reliabilist account of knowledge satisfies, in sufficient degree, the further Carnapian requirements of similarity to our ordinary concept and simplicity.

This takes us to our second question: can we accommodate Kornblith's epistemological insights without falling prey to prominent criticism of Kornblith's original account? The objections raised in Goldman (2005), concerning the tenability of the underlying methodology, are particularly relevant for our purposes. I will focus on his perhaps most central point, concerning how we are supposed to identify the natural kind corresponding to knowledge among all the natural kinds there are:

Let us grant for the sake of argument that knowledge is a natural kind. Obviously, there are many, perhaps indefinitely many, natural kinds, even indefinitely many that

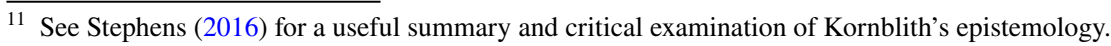


pertain to the biological kingdom. Of these indefinitely many natural kinds, which one is knowledge? Is cognitive ethology supposed to tell us? Kornblith sometimes writes as if an affirmative answer is intended, but I don't see how this can work. Kornblith argues carefully for the thesis that belief is a natural kind instantiated by animals. So perhaps knowledge is just belief; it is that natural kind. How is cognitive ethology supposed to adjudicate this issue? How is it supposed to decide that, no, knowledge is a different natural kind, inclusive of belief but more? (Goldman 2005, 407).

In particular, how does Kornblith know that knowledge is "more than just true belief" (2002, 54):

Where does the assertion that knowledge is "more than just true belief' come from? What licenses it? Surely it doesn't come from cognitive ethology. It would have to come, one supposes, from a semantico-conceptual account of the term "knowledge". But many would say that this is precisely what philosophy, in its analytic phase, aims to provide. So that job is not taken over by biological science, as Kornblith often suggests that it is (Goldman 2005, 407).

Goldman's point is that Kornblith, notwithstanding his lack of sympathy for conceptual analysis, still needs to appeal to such analysis in order to defend his identification of knowledge with a particular natural kind, such as the (alleged) natural kind of reliably acquired true belief.

At the most general level, the problem is one of access: how can we have access to, and refer to, the phenomenon of knowledge except via our concept of knowledge ${ }^{12}$ Surely, Goldman is right in objecting that even Kornblith needs to have some insight into our intuitive concept of knowledge in order to solve this problem. The question is how deep that insight needs to be. In his response to Goldman on this point, Kornblith asks us to consider an early chemist interested in the nature of acids:

The term "acid" was widely used before there was any real understanding of what it is that makes something an acid. So this chemist has vinegar (which is a dilute solution of acetic acid), hydrochloric acid, aqua regia (a mixture of hydrochloric acid and sulphuric acid) available in his laboratory, and he is trying to determine what, if anything, these various substances have in common. He believes they are all members of a single natural kind, and he is interested in determining what it is that makes them members of that kind. He has some views about what these substances have in common-many of which are mistaken—but instead of analyzing his concept of acid, he turns to the workbench and tries to figure out what these substances actually have in common. No one doubts the coherence of this project (Kornblith 2005, 429).

\section{Kornblith continues:}

Now imagine that another investigator hears about this project and announces that he wishes to help out. He too is going to find out what all acids have in common, and he has a number of samples of would-be acids which will form the basis of his investigation. Now suppose that the samples which this investigator is examining include shoes, ships, sealing wax and his pet dog. Clearly something has gone

$\overline{12}$ A similar objection to natural kind epistemology is raised in Kumar (2014). 
wrong. This second investigator is not engaged in the same project as the first, and it will be immediately obvious to anyone looking on that this is so. The same is true if this investigator has samples which are members of a single natural kind, but one nowhere in the vicinity of an acid: say, a dog, a cat, a cow and a sheep (2005, 429430).

How, then, are we to explain the mistake that the second investigator is making?

Notice that the amount of conceptual analysis needed to rule out the bizarre or misguided investigator is utterly trivial. What is needed is not a detailed and finegrained investigation of the concept of an acid; one certainly wouldn't want to devote two thousand years to arguing about the precise contours of the concept before ruling out these mistakes and getting on with the real work of studying acids. No such detailed investigation is necessary ... My view is that a proper study of knowledge requires no more - and no less-by way of conceptual analysis than is needed in the chemical case (Kornblith 2005, 430).

As has probably already struck the reader, Kornblith's response to Goldman on this issue is practically identical to Carnap's insistence that the first step in the explication of a given concept is the elucidation of the explicandum, a step that serves the purposes of zooming in on the relevant ordinary concept but, in so doing, need not, and typically does not, involve an outright conceptual analysis. Carnap explains:

An indication of the meaning with the help of some examples for its intended use and other examples for uses not now intended can help the understanding. An informal explanation in general terms may be added. All explanations of this kind serve only to make clear what is meant as the explicandum; they do not yet supply an explication, say a definition of the explicatum; they belong still to the formulation of the problem, not yet to the construction of an answer (Carnap 1950,4).

Hence, what appears to be an ad hoc addition to Kornblith's theory, unlikely to satisfy a determined opponent, turns out to be an integral part of a long and prominent methodological tradition in analytic philosophy. The bottom line is that explicationist epistemology contains within itself the resources to deal with the kind of objection that Goldman raises. Indeed, the problem does not even arise within explicationism.

Not only can we harvest Kornblith's epistemological insights without significant loss in the explicationist framework, which is historically more respectable and less idiosyncratic than Kornblith's own methodology; this can be done in a way that avoids the problem of access raised by Goldman. Finally, there is no reason to question the internal coherence of an explicationist rendering of natural kind epistemology.

\section{Explication and Knowledge First Epistemology}

In his seminal Knowledge and Its Limits (KL), Timothy Williamson (2000) famously defends his knowledge first approach to epistemology, wherein knowledge is treated as a primitive, unanalyzable concept. In a central argument for this position, Williamson refers to the sobering fact that epistemologists so far have been unable to agree on an analysis of knowledge that can do justice to our intuitions in Gettier cases. This leaves us, supposedly, with the following two options: either we continue the seemingly 
fruitless project of seeking a correct analysis of our concept of knowledge, or we give up on this project and take knowledge to be an unanalyzed, even unanalyzable, concept. Williamson's book is a sustained argument in favor of the viability and attractiveness of the second option. I will refer to this argument as his Gettier-argument.

Let us take a closer look at the argument. Williamson, in the introduction to KL $(2000,2)$, characterizes the orthodoxy in epistemology as follows:

Knowledge is merely a peculiar kind of true beliefs. Since Gettier showed that even justified true belief is insufficient for knowledge, epistemologist have expended vast efforts attempting to state exactly what kind of true belief knowledge is ... On such a view, Knowledge is to be explained in terms of belief... The converse attempt to explain belief in terms of knowledge sounds eccentric and perverse. To summarize this orthodoxy: belief is conceptually prior to knowledge.

Williamson proceeds (2000, 2-3): "The orthodox claim is frequently taken for granted, rarely supported by argument. Why should we suppose that belief is conceptually prior to knowledge?" The first answer Williamson considers rests on the proposal "that since knowledge entails belief but not vice versa, the entailment should be explained by the conjunction of belief with whatever must in fact be added to belief to yield knowledge - truth and other more elusive features". The upshot of the discussion is that the fact " $[\mathrm{t}]$ hat belief is necessary but insufficient for knowledge does not show that belief is conceptually prior to knowledge", meaning that "[t]he orthodox claim would require a deeper defence".

Williamson goes on to discuss and reject another type of defense, observing that "[s] ome epistemologists defend the conceptual priority of belief over knowledge by citing their favoured analyses of knowledge in terms of belief" (2000, 3-4), writing in response (2000, 4):

This book makes no attempt to survey even the most salient analyses of knowledge proposed in recent decades and the counterexamples to which they succumb; many other authors have already done that adequately. It will be assumed, not quite uncontroversially, that the upshot of that debate is that no currently available analysis of knowledge in terms of belief is adequate (not all parts of the book depend on that assumption). Consequently, the supposed conceptual priority of knowledge over belief is not to be defended by appeal to a particular analysis of knowledge in terms of belief.

Williamson also dismisses the proposal that "even if all currently available analyses of knowledge in terms of belief are circular or fall to counterexamples, some of them are sufficiently good approximations to indicate strongly that a further refinement on similar lines will eventually succeed" (2000, 4).

All this leads up to Williamson's project in KL of providing a new framework for epistemology in which knowledge is a primitive notion which, rather than being itself explained, can be used to explain other things (5):

A chief aim of this book is to develop a rigorous way of doing epistemology in which knowledge is central, and not subordinate to belief. It enables us to abandon the attempt to state necessary and sufficient conditions for knowledge in terms of belief without abandoning epistemology itself. Indeed, by abandoning that fruitless search we can gain insight into epistemological problems, because we are freed to use the notion of knowledge as an instrument of understanding in ways that its subordination to belief would not permit. 
Now the closest Williamson gets to providing an account of knowledge is his characterization of it in terms of a few general principles. Letting FMSO stands for "factive mental state operator", they are:

(F1) If $\Phi$ is an FMSO, from "S $\Phi$ s that A" one may infer " $\mathrm{A}$ ".

(F2) "Know" is an FMSO.

(F3) If $\Phi$ is an FMSO, from "S $\Phi$ s that A" one may infer "S knows that A".

Examples of FMSOs are "remember","see", "hear", and so on (2000, 36-37). In the case of remember, (F1) states that, if S remembers that A, then A is true, and (F3) states that if $\mathrm{S}$ remembers that $\mathrm{A}$, then $\mathrm{S}$ knows that A (for further explanations and details see $\mathrm{KL}$, Sect. 1.4.) Thus, the principles together express that knowledge is $a$ most general factive mental state. They do not express that knowledge is the most general factive mental state. There could be other most general factive mental states, but, if so, they are logically equivalent to knowledge (2000, 39, notation adapted):

For let "schnow" be any term governed by (F2') and (F3'), the results of substituting "schnow" for "know" in (F2) and (F3) respectively. By (F2) and (F3'), from "S knows that A" one may infer "S schnows that A". Similarly, by (F2') and (F3), from "S schnows that A" one may infer "S knows that A". Thus "schnow" is logically equivalent to "know".

Obviously, this characterization of knowledge using (F1)-(F3) does not state necessary and sufficient conditions for knowledge for this reason alone and, hence, does not amount to a conceptual analysis of knowledge (in terms of belief), which for Williamson, of course, is the desired outcome.

Is this characterization something we could embrace as explicationist? To answer this question, we need to look more closely at Carnap's second requirement on an explication (my emphasis):

2. The characterization of the explicatum, that is, the rules of its use (for instance, in the form of a definition), is to be given in an exact form, so as to introduce the explicatum into a well-connected system of scientific concepts.

Clearly (F1)-(F3) specify rules of use for the concept of knowledge. To be sure, they do not do this in the form of a definition, but for Carnap this is not necessary. Hence, the fact that Williamson's characterization does not qualify as a conceptual analysis or definition does not prevent it from being an explication. ${ }^{13}$

\footnotetext{
13 In his discussion of the distinction between formalization and interpretation, Carnap states that an axiomatic characterization by itself does not explicate the concepts in question; an interpretation of the terms must be added (1950, 16-18). In this connection, he contrasts Frege's and Peano's systematizations of elementary arithmetic, stating that only Frege's system achieves an explication of ordinary arithmetical concepts since only it defines those terms by explicit definitions. Peano's system, on the other hand, is compatible with many, indeed infinitely many, interpretations of the primitive terms and, for that reason, does not amount to an explication. Applied to the current discussion, we noted that $(\mathrm{F} 1)-(\mathrm{F} 3)$ are together insufficient to characterize knowledge uniquely, but only up to logical equivalence, making them strictly speaking compatible with other, "non-knowledge", interpretations. I leave it open here whether or not these considerations are sufficient to shed doubt on the notion that Williamson's characterization of knowledge can be viewed as an explication in Carnap's strict sense.
} 
Knowledge, as characterized by Williamson, is then used to shed light on various other concepts and phenomena, including "belief", "justification", "evidence", "evidential probability" and "assertion". For instance, Williamson's well-known $\mathrm{E}=\mathrm{K}$ principle states that there is no distinction to be drawn between our evidence and our knowledge; they are one and the same. Furthermore, knowledge plays a role in the conditions under which our true beliefs are stable and our actions successful. For example, "[i]f your cognitive faculties are in good order, the probability of your believing $\mathrm{p}$ tomorrow is greater conditional on your knowing p today than on your merely believing p truly today" $(2000,79)$.

In some cases, Williamson claims that knowledge figures in what are plausibly lawlike generalizations, e.g., generalizations linking knowledge to stable true belief or successful action. This aspect of Williamson's epistemology fits nicely into the Carnapian framework, of course, wherein the fruitfulness of empirical concepts resides in their ability to figure in lawlike generalizations. In other cases, the relationship is not of a causal nature, as when knowledge is linked to evidence or assertion. The latter fact complicates Williamson's assimilation within explicationist epistemology on a strict interpretation of Carnap's requirements. However, one could think of Williamson's enterprise from the perspective of the broader notion of fruitfulness alluded to in Sect. 2, according to which an explication of knowledge is fruitful if it does some explanatory work, whether or not it is fruitful in the more narrow sense of figuring in the formulation of lawlike generalization (or provable theorems).

In our treatment of Kornblith, we asked whether his insights could be accommodated within explicationism in a way that naturally neutralizes prominent criticism. The same question can be raised for Williamson mutatis mutandis. For Williamson, as for Kornblith, epistemology is not about our concept of knowledge but about knowledge itself. As Williamson puts it in his 2007 book The Philosophy of Philosophy (PP), "[t]he primary concern of epistemology is with the nature of knowledge, not with the nature of the concept of knowledge" (206). Applied to Gettier cases, this means, Williamson thinks, that our intuitions are about knowledge and not about our concept of knowledge. More precisely, the thought experiments involved, properly conducted, are taken to shed unmediated light on facts of metaphysical necessity and possibility. As Frank Jackson (2009) notices in his critical notice of PP, Williamson's stance gives rise to problems about our access to the facts in question, problems that, one could add, parallel those raised by Goldman in his critique of Kornblith. For how can we access knowledge and its metaphysical properties except via our concept of knowledge? Jackson's answer is that we cannot: "[i]nasmuch as these kinds of thought experiment [in Gettier cases] can inform us about questions of metaphysical necessity and possibility, they do so via what they tell us about conceptual necessity and possibility" (Jackson 2009, 106).

Williamson, in his reply to Jackson, questions the very idea of conceptual necessity. "In effect", he writes, "my book argues that there is no such thing as conceptual necessity" (Williamson 2009, 128). Whatever the merits of Williamson's defense, which is certainly not standard, the problem of access, again, does not even arise for explicationism. The first step of an explication of knowledge, we recall, is the elucidation of the explicandum, the purpose of which is to distinguish the relevant concept to be explicated from other similar concepts. Crucially, remembering Carnap's own words, this step need not involve giving a full conceptual analysis. A few examples and an informal explanation will often do the job quite nicely. So, once again, the problem of access has a perfectly natural and straightforward solution within explicationist epistemology. This means that we can, from the perspective of a long methodological tradition, appreciate much of what Williamson 
says about knowledge in a way that is independent of his more controversial rejection of conceptual necessity. ${ }^{14}$

There is, however, one remaining hurdle for anyone wishing to assimilate Williamson's epistemology within explicationism. As we saw, the Gettier problem is not a knockdown argument against any explication of knowledge. Whether an explicatum that fails the Gettier test is satisfactory will depend not only on the extent to which it is similar to the explicandum, but also on how well it fares with regard to exactness, fruitfulness and simplicity. Yet the conclusion of Williamson's Gettier argument is that the concept of knowledge needs to be thought of in an entirely new way solely on the basis of proposed definitions failing to be similar to the ordinary concept with regard to Gettier intuitions. For an explicationist, this is overreacting to the Gettier problem. So is there any grain of truth in the Gettier argument that the explicationist could appreciate? Perhaps only this: that previous conceptual analyses of knowledge have all failed as such because of Gettier cases and that this is itself an argument for radical rethinking.

\section{Williamson on Philosophical Methodology}

As we saw, while much of what Williamson writes about knowledge can be appreciated from an explicationist standpoint, this does not go for everything he writes about it. His commitment to conceptual analysis is also seriously in doubt. What, then, is his philosophical methodology?

It is important to be clear about the scope of Williamson's critique of the traditional view in epistemology. In particular, his critique assumes that various definitions of knowledge in the literature are offered as conceptual analyses (CA). The concept of knowledge is assumed to be analyzable in terms of 'belief' and other concepts similar to how 'bachelor' is analyzable in terms of 'man' and 'unmarried'. Who is to decide whether a given conceptual analysis is correct? Bearing in mind Williamson's general doubts about experimental philosophy and his corresponding respect for philosophical expertise (e.g. Williamson 2013), the authority to rely upon, in his view, is the competent philosopher in the relevant discipline, who has the relevant skill in applying the concepts in question. Thus, Williamson, in Knowledge and its Limits (KL), assumes something like this:

(CA1) We may, when defining a philosophical concept $X$, not depart from the ordinary use of $\mathrm{X}$, as judged by competent philosophers in the relevant discipline.

Specifically ("K” for "Knowledge"),

(K1) We may, when defining the concept of knowledge, not depart from the ordinary use of knowledge, as judged by competent epistemologists.

If we combine (CA1) with Williamson's firm view that, according to the ordinary use of knowledge (as judged by a competent epistemologist), people in Gettier cases do not know, the result is that any acceptable definition of knowledge should have this verdict as a consequence. In other words:

\footnotetext{
${ }^{14}$ Following the publication of The Philosophy of Philosophy there was an interesting debate between Williamson and Kornblith on philosophical methodology (Kornblith 2009, Williamson 2009). As one could expect, they agree on many broader issues but sometimes disagree at the level of detail. Thus, both authors recognize the need for empirical input as well as armchair reasoning in philosophy. Their dispute concerns rather the proper balance between the two. Symptomatically, neither author identifies what I have called the problem of access - a problem they share - in the work of the other.
} 
(K2) We may, when defining the concept of knowledge, not depart from the ordinary use of knowledge, as judged by competent epistemologists; in particular, the resulting concept should have as a consequence that people do not know in Gettier cases.

Now, it is probably correct to say that most advocates of post-Gettier definitions of knowledge have put forward their accounts as conceptual analyses in the spirit of (K2). Yet, this is not the only possible choice. As we have seen, there is a prominent tradition in analytic philosophy according to which definitions of concepts should be understood instead as explications or, more generally, (rational) conceptual reconstructions. There is no reason in principle why the pre-systematic concept explicated could not be that of knowledge. That knowledge cannot be analyzed does not mean that it cannot be explicated. In fact, that knowledge cannot be analyzed in terms of belief or other more basic concepts, if we grant Williamson this much, does not mean that knowledge cannot be explicated in terms of belief or other more basic concepts.

As a matter of fact, attempting a conceptual reconstruction of knowledge is an option that seems broadly available to Williamson himself in the light of some of his other remarks on philosophical methodology. While much of the reasoning in KL arguably relies on appeal to pre-systematic judgement, often in the spirit of an orthodox view on conceptual analysis, Williamson's discussion of the concept of evidence, in Ch. 9 of $\mathrm{KL}$, is notably different. There, Williamson observes that his propositional account of evidence fails to do justice to all our pre-systematic judgements $(2000,194)$ :

Why should all evidence be propositional? It would not be on a broad interpretation of 'evidence'. In the courts, a bloodied knife is evidence. It is natural to say that my evidence that I am getting a cold includes various sensations. Some philosophers apply the term 'evidence' to non-propositional perceptual states; Quine restricts it to the stimulation of sensory receptors ... How can 'All evidence is propositional' do more than stipulate a technical use for the word 'evidence'?

In response to this rhetorical question, he writes:

Indiscriminate description of the ordinary use of a term and arbitrary stipulation of a new sense are not the only options. We can single out theoretical functions central to the ordinary concept evidence, and ask what serves them. That strategy is pursued here.

Williamson is here giving reasons to depart from the ordinary use of a term, in this case "evidence", when giving a philosophical account of the corresponding concept. We may, he suggests, depart from the ordinary use if we can single out theoretical functions central to a given concept and ask what serves them. If we find a concept that serves these functions well, we may very well be satisfied with that concept.

Now what serves the central functions of $\mathrm{X}$ need not itself be an $\mathrm{X}$. This applies to concepts as a special case. What serves the central functions of a concept $\mathrm{X}$ need not itself be identical to that concept. There are many examples in science of concepts that are refined, and therefore non-identical, versions of everyday concepts. The refined concept serves the central functions of the everyday concept, in a particular scientific context. Thus, the concept of intelligence, as it is used in cognitive psychology, serves the functions of the everyday concept of intelligence in psychological investigations; the concept of a market, as it is used in economic theory, serves the functions of the everyday concept of a market in economical investigations; and so on. 
Clearly, then, Williamson is in the above quote in effect legitimizing a reconstructive approach to philosophical concepts. The general principle seems to be this ("CR" for "Conceptual Reconstruction"):

(CR1) We may, when defining a concept X, depart from the ordinary use of X, as judged by competent philosophers in the relevant discipline, if this results in a new concept that serves the theoretical functions central to $\mathrm{X}$.

This aspect of Williamson's methodological remarks raises the question why a reconstructive approach is legitimate with respect to evidence and not with respect to knowledge. Why insist on a conceptual analysis, if such there be, with regard to knowledge but not with regard to evidence? For the following claim is a direct consequence of (CR1):

(K3) We may, when defining the concept of knowledge, depart from the ordinary use of knowledge, as judged by competent epistemologists, if this results in a new concept that serves the theoretical functions central to knowledge.

Specifically,

(K4) We may, when defining the concept of knowledge, depart from the ordinary use of knowledge, as judged by competent epistemologists, such as its use in Gettier cases, if this results in a new concept that serves the theoretical functions central to knowledge.

Unfortunately, (K4) is in direct conflict with Williamson's commitment to (K2), repeated here (with added emphasis) for ease of reference:

(K2) We may, when defining the concept of knowledge, not depart from the ordinary use of knowledge, as judged by competent epistemologists; in particular, the resulting concept should have as a consequence that people do not know in Gettier cases. ${ }^{15}$

Williamson's openness to conceptual reconstruction is even more salient in his account of evidential probability, i.e. the probability of something given the evidence (KL, chapter 10). On his account, evidential probability is governed by the familiar Kolmogorov axioms. This account implies that all logically equivalent propositions have the same probability on the evidence, an implication that prompts Williamson to make the following remark $(2000,212)$ :

\footnotetext{
${ }^{15}$ It might be objected that there is a difference between 'knowledge' and 'evidence' justifying different treatment of the two concepts. One difference (suggested by a referee) is that we take an interest in knowledge per se whereas our interest in evidence is only instrumental. The question is whether it is a relevant difference. The general principle would be that we should be more true to the phenomena when defining things that we take an interest in per se, than when defining things that we take only an instrumental interest in. However, I see no concrete reasons to subscribe to this principle nor have I seen any indication that Williamson would subscribe to it. Williamson thinks, however, that there is an important difference between 'knowledge' and 'evidence': knowledge is a conceptually prior to evidence. Perhaps we should be more true to the phenomena when defining things that are conceptually more fundamental. It would follow that we should treat 'knowledge' differently than 'evidence'. In the former case, all the nuances of the ordinary concept are relevant, including those emanating from Gettier intuitions, whereas in the latter case they are not. Unfortunately, this argument already presupposes Williamson's knowledge first approach (that 'knowledge' is conceptually fundamental) and cannot be used in the methodology underlying his Gettier argument for that approach.
} 
The reason is not that a perfectly rational being would have the same credence in them [the logically equivalent propositions], for the irrelevance of such beings to evidential probability has already been noted. The axioms are not idealizations, false in the real world. Rather, they show what kind of thing we are choosing to study. We are using a notion of probability which (like the notion of incompatibility) is insensitive to differences between logically equivalent propositions. We thereby gain mathematical power and simplicity at the loss of some descriptive details (for example, in the epistemology of mathematics): a familiar bargain.

Thus, Williamson recognizes that his account of evidential probability is not true to all the phenomena. In particular, it departs from the ordinary understanding in not being sensitive to differences between logically equivalent propositions. This is excusable, Williamson thinks, because the account thereby gains mathematical power and simplicity.

Combining these considerations with (CR1), we get a more specific reconstructivist principle:

(CR2) We may, when defining a concept X, depart from the ordinary use of $\mathrm{X}$, as judged by competent philosophers in the relevant discipline, if this results in a new concept $Y$ such that (a) Y serves the theoretical functions central to X, and (b) adopting $\mathrm{Y}$ rather than $\mathrm{X}$ implies an increase in mathematical power and simplicity.

But once this much is conceeded, why could we not argue in precisely the same fashion regarding the concept of knowledge? For the following claim is a direct consequence of (CR2):

(K5) We may, when defining the concept of knowledge, depart from the ordinary use of knowledge, as judged by competent epistemologists, e.g. in relation to Gettier cases, if this results in a new concept of knowledge such that (a) this new concept serves the theoretical functions central to knowledge, and (b) adopting the new concept rather than the old implies an increase in mathematical power and simplicity.

How is it that an account of knowledge must be true to all the phenomena, including all the vagaries of Gettier cases, when this is not required of an account of evidential probability? Why not sacrifice faithfulness to Gettier judgements in return for greater simplicity and other theoretical values when explaining knowledge just as Williamson is willing to sacrifice descriptive details for greater simplicity and the like when explaining evidential probability?

Williamson's (2007) book The Philosophy of Philosophy (PP) is devoted specifically to issues of philosophical methodology. The reader might therefore reasonably expect a more developed and coherent methodology in comparison to KL. Alas, this is not obviously the case. Rather, PP suffers, in my view, from essentially the same methodological ambiguity as KL does. Although PP, like KL, starts off firmly in the conceptual analysis camp, it drifts towards a reconstructive methodological perspective, and the "Afterword" - a compelling and sometimes devastating critique of the state of contemporary analytic philosophy - is written very much in the spirit of rational reconstruction.

Thus, in the bulk of PP, Williamson offers an extended defense of the use of intuitions as evidence in philosophy (although he prefers to label them "judgements"). Any merely psychological understanding of philosophical intuition is rejected; in standard cases, our intuitions are about facts (as in true propositions) and commonly amount to knowledge (according to the "principle of knowledge maximization", a knowledge version of Davidson's principle of charity). General skepticism about our intuitions, "judgement skepticism" in 
Williamson's terms, is placed on a par with general skepticism and, as such, rejected. This does not mean, however, that our intuitions cannot lead us astray:

None of the foregoing arguments provides any guarantee that judgement skepticism is not correct for some types of judgement; 'common sense' is sometimes wrong. But if it is accepted in such cases, that should be on the basis of evidence specific to those types of judgement, not on the basis of general skeptical fallacies.

This remark sums up the position Williamson takes on pre-systematic judgements in PP when he is in his conceptual-analytical mode; they are to be respected and treated as evidence in general, but in some cases departures from judgements might be legitimate if warranted by specific evidence, e.g. evidence suggesting that particular judgements may be wrong or unreliable. Thus we resist, he thinks, our pre-systematic judgement in favor of the Naïve Comprehension principle for sets, by which any predicate has a set as its extension, because we know, specifically, that it is affected by Russell's paradox (2007, 216-217). What is offered here is, in effect, a slightly less conservative version of (CA1):

(CA2) We may, when defining a philosophical concept X, not depart from the ordinary use of $\mathrm{X}$, as judged by competent philosophers in the relevant discipline, except in cases in which our evidence strongly indicates that the judgement is inaccurate in the particular case.

By contrast, the "Afterword" takes the mathematician to be a useful role model for philosophers $(2007,289)$ :

Beyond rigor and precision, mathematics has less obvious values to teach. In particular, a mathematical training makes one appreciate the importance of the aesthetics of definitions. Experience shows that a mathematician or logician with no ability to discriminate between fruitful and unfruitful definitions is unlikely to achieve much in research. Such discriminations involve a sort of aesthetic judgement. The ugly, convoluted, ramshackle definitions of concepts and theses that philosophers seem to feel no shame in producing are of just the kind to strike a mathematician as pointless and sterile. Of course, it is notoriously hard to explain why aesthetic criteria are a good methodological guide, but I would be dangerously naïve to abandon them for that reason.

This passage, and others like it, indicates that Williamson is in fact sympathetic to reconstructive methodology, broadly in the sense of (CR2). This makes him vulnerable to criticism of the kind I have already offered. To reiterate, if things like aesthetic judgement, elegance and simplicity are good methodological guides, not least when defining important philosophical concepts, why are we not allowed to appeal to those very values when defining the concept of knowledge? In particular, why would it be wrong to sacrifice faithfulness to the Gettier phenomena in return for, say, an elegant and fruitful definition of knowledge? How is that we are somehow restricted to conceptual analysis in the case of knowledge but, apparently, not in the case of other concepts?

For the record, in PP Williamson rarely misses an opportunity to reaffirm his commitment to the judgement that people in Gettier cases fail to know, which he refers to as the "Gettier proposition". Here is one instance $(2007,216)$ :

Many people grasp the concepts in question without feeling inclined to assent to the Gettier proposition. What they lack is a skill in applying those concepts which goes beyond mere possession. Those who respond correctly to the Gettier case, presented 
in imagination or perception, do so on the basis of skill in applying the concepts; possessing them is insufficient.

Although Williamson in PP sees some indirect or residual value in post-Gettier research, he remains committed to its ultimate and predictable failure to provide an analysis of the concept of knowledge (2007, 281, footnote 1). Having observed advances in our understanding of modal terms following philosophical investigation, he remarks:

This guarded optimism about philosophical progress is consistent with the pessimism in $[\mathrm{KL}]$ about the prospects of the post-Gettier program of analyzing the concept of knowledge and similar programs of analyzing other philosophically significant concepts. Such programs did make progress in clarifying the relations between the concepts under study (and between the things to which those concepts refer). What they failed to make plausible was that the eventual outcome of such progress would be anything like an analysis in the intended sense (necessary and sufficient conditions stated in non-circular terms, perhaps meeting further conditions). Take any concept that is indefinable in the relevant sense: the vain program of analyzing it in terms of more basic concepts, if conducted by able and honest people over several decades, would lead to some progress of this kind.

The upshot of this discussion is that it is not easy to combine the various elements of Williamson's philosophical methodology into a coherent picture. Especially his relatively strict reliance on philosophical intuition, or judgement, in the case of knowledge and his openness to conceptual reconstruction, within limits, regarding other concepts such as evidence or evidential probability, is puzzling.

\section{Conclusion}

Explicationist epistemology can unify epistemology by providing a general, historically respectable methodological foundation and solve some of its long-standing problems (Olsson 2017). The unificatory benefits would include all the systematic advantages that normally follow from something being subsumable under a general and historically respectable standard methodology. Many other methodologies (experimental philosophy, conceptual analysis, and so on) can be seen as limit or boundary cases of explication, typically emphasizing similarity to our ordinary concepts. The output of those methodologies is often useful in the explicationist enterprise, which is the basis for the more cheerful suggestion that they can be viewed as sub-methodologies to explicationism. Equally important, explicationist epistemology, unlike conceptual analysis, is immune to the paradox of analysis and, with the appropriate caveats, essentially to the Gettier problem as well.

My focus here was on Kornblith's natural kind epistemology and Williamson's knowledge first epistemology, both emphasizing the explanatory role of knowledge (and a dissatisfaction with conceptual analysis), and the extent to which they allow for assimilation into explicationist epistemology. Thus, my aim was not to conduct a critical examination of natural kind or knowledge first epistemology. Rather, I assumed, for the sake of the argument, that what Kornblith and Williamson say about knowledge is true, asking instead the somewhat unusual question whether their insights could be accommodated by an explicationist.

In this connection, I argued that the insights in natural kind epistemology can in fact be harvested by an explicationist, given a plausible principle bridging the gap between a phenomenon (knowledge) figuring in natural regularities and the corresponding concept 
figuring in lawlike generalizations describing those regularities. The result plausibly satisfies Carnap's conditions of exactness and fruitfulness (as well as, arguably, similarity and simplicity). Furthermore, the problem of access in effect raised by Goldman, in his critique of Kornblith, does not arise in explicationism. Hence, Kornblith's theory, thus reconstructed, delivers a coherent account of knowledge.

Turning to Williamson, his characterization of knowledge as a most general factive mental state qualifies in principle as an explication, which does not have to come in the form of a definition. We found that what Williamson says about the causal role of knowledge is quite congenial to Carnap's account of fruitfulness of empirical concepts. However, a full explicationist construal of Williamson's epistemology requires a broader conception of fruitfulness, according to which a concept is fruitful if it is of some theoretical value. Williamson, too, faced a problem of access, which for the same reason as before is non-existent in an explicationist framework. Even so, from the perspective of explicationism, Williamson's rejection of the very idea of giving an account of knowledge in terms of necessary and sufficient conditions amounts to an overreaction to the Gettier problem, although an explicationist can appreciate that previous conceptual analyses of knowledge have failed because of Gettier cases and that this is an argument for radical epistemological rethinking. Turning to Williamson's actual methodology, I found it difficult to combine its various elements into a coherent whole.

Acknowledgements Open access funding provided by Lund University.

Open Access This article is licensed under a Creative Commons Attribution 4.0 International License, which permits use, sharing, adaptation, distribution and reproduction in any medium or format, as long as you give appropriate credit to the original author(s) and the source, provide a link to the Creative Commons licence, and indicate if changes were made. The images or other third party material in this article are included in the article's Creative Commons licence, unless indicated otherwise in a credit line to the material. If material is not included in the article's Creative Commons licence and your intended use is not permitted by statutory regulation or exceeds the permitted use, you will need to obtain permission directly from the copyright holder. To view a copy of this licence, visit http://creativecommons.org/licenses/by/4.0/.

\section{References}

Baumann, P. (2016). Epistemic contextualism: a defense. Oxford: Oxford University Press.

Brun, G. (2016). Explication as a method of conceptual re-engineering. Erkenntnis, 81(6), 1211-1241.

Carnap, R. (1950). Logical foundations of probability. Chicago: Chicago University Press.

Cat, J. (2019). The Unity of Science, The Stanford Encyclopedia of Philosophy (Fall 2017 Edition), E. N. Zalta (ed.), <https://plato.stanford.edu/archives/fall2017/entries/scientific-unity/>.

Cordes, M., and Siegwart, G. (2019). Explication. In The internet encyclopedia of philosophy. Accessed 20 Aug 2019. https://www.iep.utm.edu/explicat/.

Dutilh Novaes, C., \& Reck, E. (2017). Carnapian explication, formalisms as cognitive tools, and the paradox of adequate formalization. Synthese, 194(1), 195-215.

Goldman, A. I. (1999). Knowledge in a social world. New York: Oxford University Press.

Goldman, A. I. (2005). Kornblith's naturalistic epistemology. Philosophy and Phenomenological Research LXXI, 2, 403-410.

Gustafsson, M. (2013). Quine's conception of explication—and why it isn't carnap's. Ch. 24 in a companion to W. V. O. Quine, G. Harman and E. Lepore (eds.), Wiley Online Library. https://onlinelibrary.wiley.com/ doi/book/10.1002/9781118607992.

Hempel, C. (1952). Fundamentals of concept formation in empirical science. Foundations of the Unity of Science II, 7, 1-88.

Jackson, F. (2009). Thought experiments and possibilities. Analysis Reviews, 69(1), 100-109.

Koch, S. (2019). Carnapian explications, experimental philosophy, and fruitful concepts. Inquiry, 62(6), $700-717$.

Kornblith, H. (2002). Knowledge and its place in nature. Oxford: Oxford University Press.

Kornblith, H. (2005). Replies to Alvin Goldman, Martin Kusch and William Talbott. Philosophy and Phenomenological Research, 71(2), 427-441. 
Kornblith, H. (2009). Timothy Williamson's the philosophy of philosophy. Analysis Reviews, 69(1), 116-125.

Kumar, V. (2014). 'Knowledge' as a natural kind term. Synthese, 191, 439-457.

Lehrer, K. (1990). Theory of knowledge. London: Routledge.

Maher, P. (2007). Explication defended. Studia Logica, 86(2), 331-341.

Olsson, E. J. (2012). Reliabilism as explicating knowledge: A Sketch of an Account. In C. Jäger \& W. Löffler (Eds.), Epistemology: Contexts, values, disagreement. Frankfurt: Ontos Verlag.

Olsson, E. J. (2015). Gettier and the method of explication: a 60 year old solution to a 50 year old problem. Philosophical Studies, 172, 57-72.

Olsson, E. J. (2017). Explicationist Epistemology and Epistemic Pluralism. In A. Coliva \& N. Jang Lee Linding Pederson (Eds.), Epistemic pluralism. London: Palgrave Macmillan.

Pinder, M. (2017). Does experimental philosophy have a role to play in Carnapian explication? Ratio, 30, 443-461.

Quine, W. V. O. (1960). Word and object. Cambridge: The MIT Press.

Shepherd, J., \& Justus, J. (2015). X-Phi and Carnapian explication. Erkenntnis, 80, 381-402.

Shupbach, J. N. (2017). Experimental explication. Philosophy and Phenomenological Research, 94(3), $672-710$.

Stephens, A. (2016). A pluralist account of knowledge as a natural kind. Philosophia, 44, 885-903.

Weinberg, J. M., Nichols, S., \& Stich, S. (2001). Normativity and epistemic intuitions. Philosophical Topics, $29(1 \& 2), 429-460$.

Williamson, T. (2000). Knowledge and its limits. Oxford: Oxford University Press.

Williamson, T. (2007). The philosophy of philosophy. Malden: Blackwell Publishing.

Williamson, T. (2009). Replies to Kornblith, Jackson and Moore. Analysis Reviews, 69(1), 125-135.

Williamson, T. (2013). Review of experimental philosophy: an introduction by Joshua Alexander. Philosophy, $88(3), 467-474$.

Publisher's Note Springer Nature remains neutral with regard to jurisdictional claims in published maps and institutional affiliations. 